\title{
Using Digital Images of the Zebra Finch Song System as a Tool to Teach Organizational Effects of Steroid Hormones: A Free Downloadable Module
}

\author{
William Grisham, ${ }^{*}$ Natalie A. Schottler, ${ }^{*}$ Lisa M. Beck McCauley, ${ }^{\dagger}$ Anh P. Pham, ${ }^{\ddagger}$ \\ Maureen L. Ruiz, ${ }^{\S}$ Michelle C. Fong, ${ }^{\S}$ and Xinran Cui ${ }^{\ddagger}$
}

*Department of Psychology, University of California, Los Angeles, Los Angeles, CA 90095;

${ }^{\dagger}$ Department of Psychology, Bryn Mawr College, Bryn Mawr, PA 19010; ${ }^{\ddagger}$ Interdepartmental Major

in Neuroscience, University of California, Los Angeles, Los Angeles, CA 90095; and \$ Pomona Neuroscience

Program, Harvey Mudd College, Claremont, CA 91711

Submitted January 5, 2011; Revised March 10, 2011; Accepted March 10, 2011

Monitoring Editor: Eric H. Chudler

\begin{abstract}
Zebra finch song behavior is sexually dimorphic: males sing and females do not. The neural system underlying this behavior is sexually dimorphic, and this sex difference is easy to quantify. During development, the zebra finch song system can be altered by steroid hormones, specifically estradiol, which actually masculinizes it. Because of the ease of quantification and experimental manipulation, the zebra finch song system has great potential for use in undergraduate labs. Unfortunately, the underlying costs prohibit use of this system in undergraduate labs. Further, the time required to perform a developmental study renders such undertakings unrealistic within a single academic term. We have overcome these barriers by creating digital tools, including an image library of song nuclei from zebra finch brains. Students using this library replicate and extend a published experiment examining the dose of estradiol required to masculinize the female zebra finch brain. We have used this library for several terms, and students not only obtain significant experimental results but also make gains in understanding content, experimental controls, and inferential statistics (analysis of variance and post hoc tests). We have provided free access to these digital tools at the following website: http://mdcune.psych.ucla.edu/modules/birdsong.
\end{abstract}

\section{INTRODUCTION}

The bird song system has had a long record of yielding cutting-edge findings in neurobiology. Adult neurogenesis (Alvarez-Buylla et al., 1988) and dramatic sex differences in the brain (Nottebohm and Arnold, 1976) were first described in this system. This system is still the focus of ongoing investigations on neurosteroids (Schlinger et al., 2001), learning and

DOI: $10.1187 /$ cbe.11-01-0002

Address correspondence to: Dr. William Grisham (grisham@ lifesci.ucla.edu).

(C) 2011 W. Grisham et al. CBE-Life Sciences Education (c) 2011 The American Society for Cell Biology. This article is distributed by The American Society for Cell Biology under license from the author(s). It is available to the public under an AttributionNoncommercial-Share Alike 3.0 Unported Creative Commons License (http:// creativecommons.org/licenses/by-nc-sa/3.0).

"ASCB ${ }^{(2) " ~ a n d ~ " T h e ~ A m e r i c a n ~ S o c i e t y ~ f o r ~ C e l l ~ B i o l o g y ~}{ }^{\mathbb{R}) " ~ a r e ~ r e g i s-~}$ tered trademarks of The American Society for Cell Biology. memory (Troyer and Doupe, 2000; Nordeen and Nordeen, 2004), and genes and proteins involved in vocal learning (White et al., 2006; Xie et al., 2010). The song system is also a valuable model of both the genetic and hormonal bases of sexual differentiation of nervous systems (Grisham and Arnold, 1995; Agate et al., 2003; Duncan et al., 2009).

The song system consists of a set of interconnected nuclei whose only known function is the learning and production of song (Figure 1). This system can be divided into song acquisition and song production pathways. The song acquisition pathway consists of nuclei in the anterior forebrain pathway: lateral magnocellular nucleus of anterior nidopallium (lMAN), nucleus dorsolateralis anterior thalami, pars medialis (DLM), and Area X, which is its proper name (nomenclature from Reiner et al., 2004; Nixdorf-Bergweiler and Bischof, 2007). Lesions in this pathway disrupt the acquisition (Bottjer et al., 1984; Scharff and Nottebohm, 1991; Johnson and Bottjer, 1992; Nottebohm, 2005) and maintenance of song (Williams and Mehta 1999; Roy and Mooney, 2007). The production 


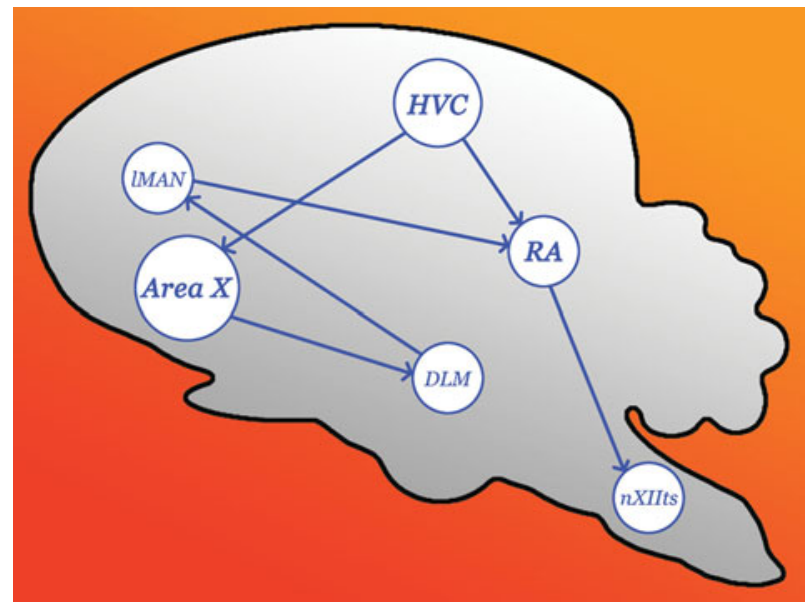

Figure 1. Semi-schematic of a sagittal view of a songbird brain highlighting the relationships among the song nuclei. RA, IMAN, Area $X$, and HVC are all telencephalic nuclei. RA, IMAN, and HVC can be considered as roughly homologous to aspects of the mammalian cortex. Area $X$ is a part of the basal ganglia and is also part of the forebrain. DLM and nXII are in the brainstem.

pathway consists of HVC (here used as a proper name), the robust nucleus of arcopallium (RA), and hypoglossal nucleus (nXII) (nomenclature from Reiner et al., 2004). Lesions of this pathway result in a loss of song (Nottebohm et al., 1976). Electrophysiological evidence suggests that song syllable timing is organized in HVC and the syllables' actual acoustic properties are organized in RA (McCasland, 1987; Vu et al., 1994; Suthers and Margoliash, 2002).

In most (but not all, cf. Brenowitz and Arnold, 1986) songbird species, the song behavior is sexually dimorphic with males singing more than females. Accordingly, in most species, the telencephalic song nuclei (Area X, HVC, and RA) are dramatically larger in males than in females (Nottebohm and Arnold, 1976; Gurney and Konishi, 1980; Grisham and Arnold, 1995; see Figure 2). This sex difference can be altered in development via the organizational effect of steroid hormones, which determine aspects of the sexual phenotype irrespective of the genetic code carried on the sex chromosomes (cf. Breedlove and Hampson, 2002; Phoenix et al., 1959). Exogenous steroid hormones, particularly estradiol, can masculinize the brain phenotype in developing female zebra finches (Gurney and Konishi, 1980; Grisham and Arnold, 1995, Grisham et al., 2008) and is also known to masculinize mammalian brains in development (cf. Breedlove and Hampson, 2002).

The rich literature on the song system, the robust difference between the sexes in the size of song nuclei, and the dramatic masculinizing effect of hormones on this system's development (Gurney and Konishi, 1980; Grisham and Arnold, 1995) make the zebra finch song system valuable for demonstrating the effects of hormones on development and sex differences in brain morphology. In particular, undergraduate neuroscience, biological psychology, and animal behavior laboratories could profit from using this system. Nevertheless, studying this system requires significant investments: supporting a bird colony and purchasing good-quality microscopes, microtomes, histological supplies for processing brains, and digital microscope cameras. Such extensive fa- cilities and equipment requirements make studying the bird song system out of reach for many institutions. We have overcome these barriers by creating a library of digital images of the bird song system and distributing it at no cost to users at the following website: http:/ / mdcune.psych.ucla.edu.

This library consists of images of female zebra finch brains used in a previously published study (Grisham et al., 2008), along with added images from control males. The females were administered different doses of estradiol at hatching, and their brains were examined and photographed in adulthood. Using this library, students not only repeat an experiment examining the relationship between the dose of estradiol and the degree of masculinization in the song system, but also extend the original experiment because they quantify images from control males that were not part of the original experiment (Grisham et al., 2008). Because of the robust sex differences and large treatment effects, even inexperienced students will obtain data yielding significant differences.

\section{METHODS}

\section{Materials}

All that is required for this laboratory is a computer. The image library (available for download at the above address) consists of the relevant images of Area X, HVC, and RA in control male and control female zebra finches, as well as females that received 5,15 , or $50 \mu$ g estradiol $\left(E_{2}\right)$ at hatching. These images were made from tissue prepared for Grisham et al., 2008, so students can refer to this article for procedural details (Pubmed Central ID \#PMC2605609). The males came from other studies in which they were treated at hatching with either blank implants (Grisham and Arnold, 1995) or implants of indomethacin, a prostaglandin inhibitor like aspirin, that had no discernable effect on the song system (Borowski et al., 2010). The male brains were prepared in an identical way to that reported in Grisham et al., 2008. Students quantify the size of song regions using ImageJ, which is a free software package that can run on any platform (National Institutes of Health, 1997).

\section{Procedure}

Students are given the following five specific objectives to focus their thinking and to help structure their journal-style laboratory report: 1) Although this module isn't an independent replication, it is still useful to see whether students' measurement and reanalysis yield the sex differences in the song system established in the literature (Nottebohm and Arnold, 1976; Grisham and Arnold, 1995). We use this as an opportunity to underscore why this step is necessary to validate their techniques and findings. We point out that there is no need to try to explore the underlying basis of a phenomenon if one cannot repeat it with the same materials. 2) To probe the sensitivity of the female zebra finch song system to $E_{2}$-induced masculinization. This study was originally motivated by another study that substantially reduced $E_{2}$ synthesis and found no impact on the masculine development of the song system (Wade et al., 1996). Nonetheless, if masculinization processes were exquisitely sensitive to $E_{2}$, the residual $E_{2}$ could have been sufficient to masculinize the system. 3) To discern whether 


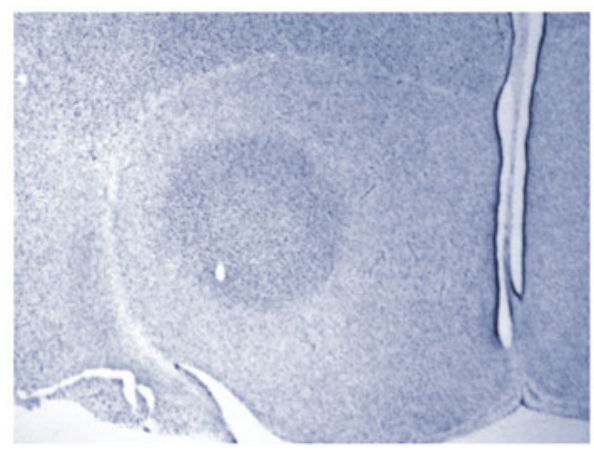

MALE - AREA X

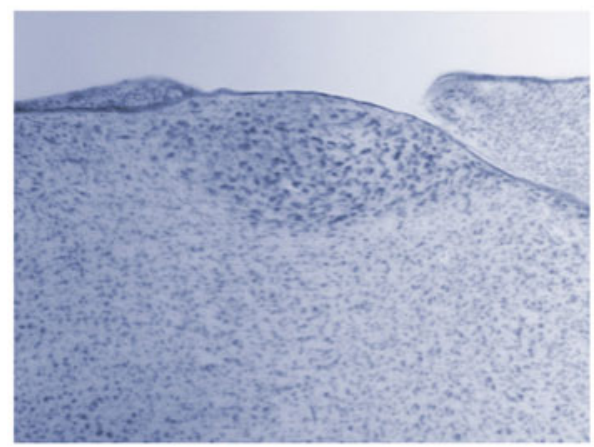

MALE - HVC

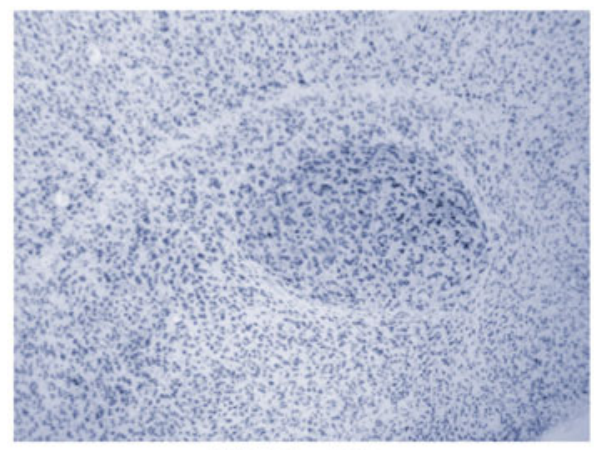

MALE - RA

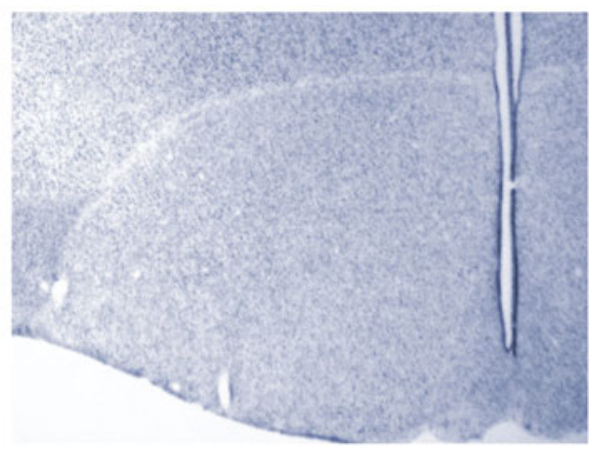

FEMALE - AREA X

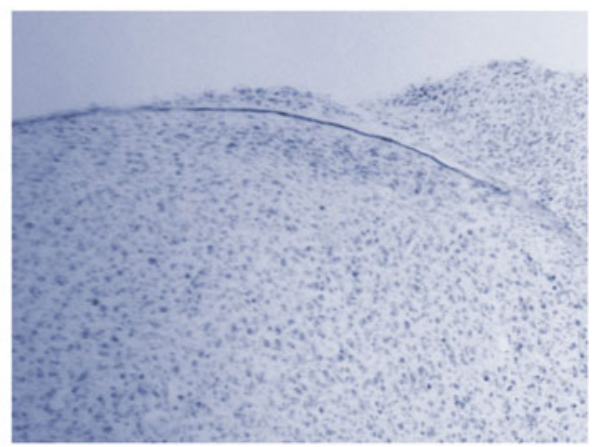

FEMALE - HVC

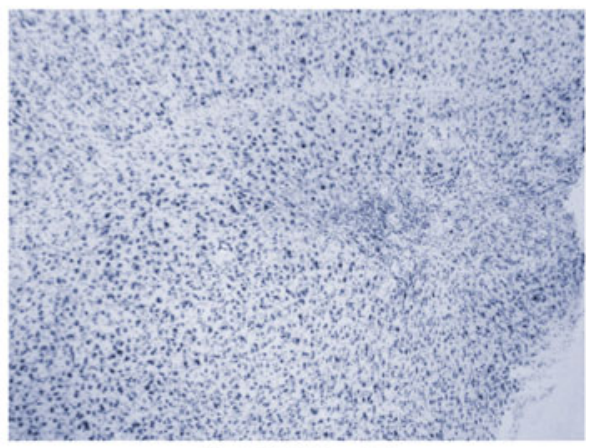

FEMALE - RA
Figure 2. Side-by-side comparisons of male and female Area X (females don't have an Area X), HVC, and RA. These images are from our library. Each individual would have multiple images from all sections across the rostral-caudal extent of a given song nucleus, so that students can determine the volume. masculinization is an all-or-none event once a threshold was reached, or whether it is proportional to the dose of $E_{2}$. 4) To ascertain whether different parts of the song system show differential sensitivity to $E_{2}$, which could provide some clues about song system development. 5) To determine whether our largest dose of $E_{2}$ will fully masculinize the song system in females to the same extent as males. We provide students with background readings (Grisham and Arnold, 1995; Breedlove and Hampson, 2002; Nottebohm, 2005; Grisham et al., 2008) as well as background lectures (see http:/ / mdcune.psych.ucla.edu/modules/birdsong) and ask them to formulate predictions based on the readings.

We use this module to teach about experimental procedures to avoid possible confounds. First, each student is assigned a total of five birds, one from each different treatment condition (control male, control female, and 5, 15, and $50 \mu \mathrm{g} \mathrm{E}_{2}$ females; see Figure 3). This balancing procedure prevents students' differential quantification style from potentially confounding the results (discussed further in the Complete Users' Manual: Thorough Guide to Obtaining and Analyzing Data for Students and Instructors, which can be found on the website). We use this design consideration to illustrate that, when extraneous variables are present and cannot be eliminated, an experiment can be designed so that they do not operate differentially across treatments and potentially confound the results. Second, students are kept blind to the sex and treatment of the birds while they are making measurements of the song system, and we explain to students that this controls for bias.

Using NIH ImageJ, students make cross-sectional measurements to the nearest $0.01 \mathrm{~mm}^{2}$ of all the images of Area $\mathrm{X}$, HVC, and RA. PDFs on the website, including the Complete Users' Manual: Thorough Guide to Obtaining and Analyzing Data for Students and Instructors, and FAQs provide details on quantification, including pitfalls. Students can convert these measurements to volumes because they know the 


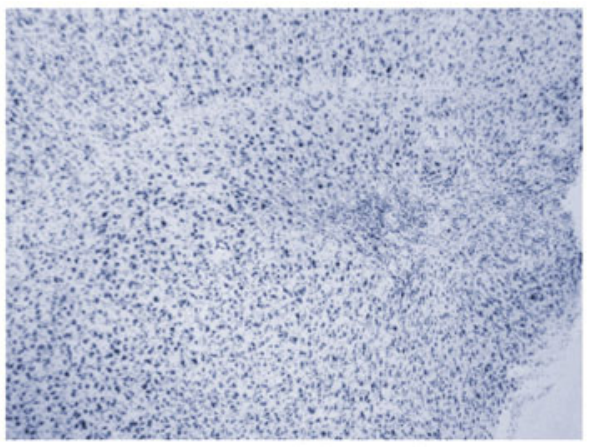

FEMALE CONTROL

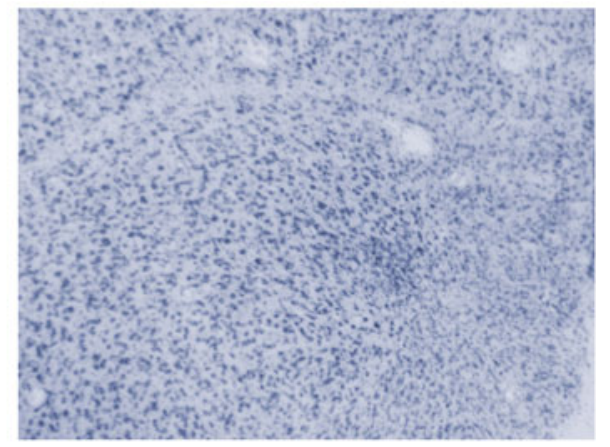

FEMALE $5-\mu \mathrm{g} \mathrm{E}_{2}$

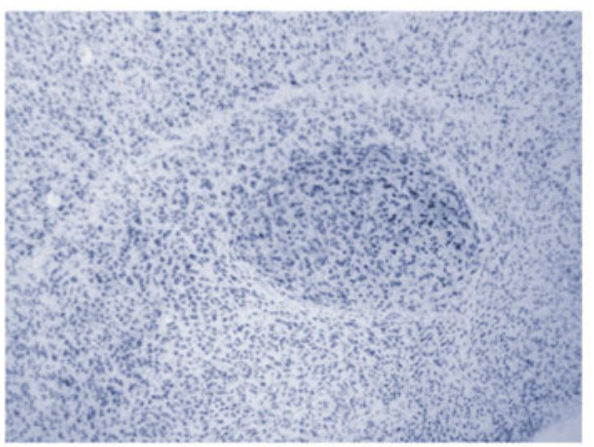

MALE CONTROL

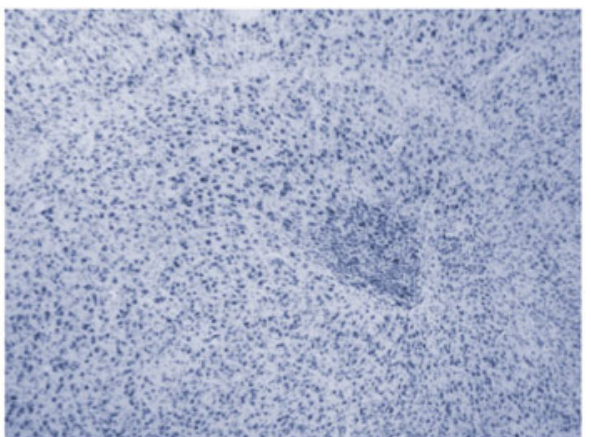

FEMALE $15-\mu \mathrm{g} \mathrm{E}_{2}$

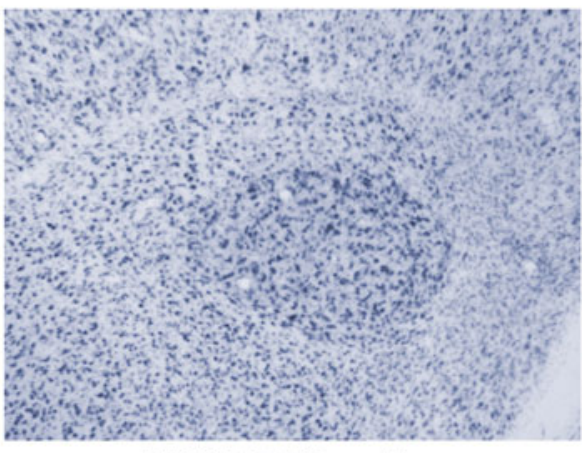

FEMALE $50-\mu \mathrm{g} \mathrm{E}_{2}$
Figure 3. RA in a single section from each of our groups. Differences are quite evident and easy to quantify. (Again, students quantify multiple sections for each nucleus of each bird.) sampling interval between sections (see the Complete Users' Manual on our website).

Students combine their data, and ultimately several birds' data are represented in each treatment condition. A master spreadsheet containing all the data along with information about the sex and treatment of each bird is distributed to each student. (Instructors may access a spreadsheet by going to http://mdcune.psych.ucla.edu/faculty and setting up a free faculty account.) Students are guided in analyzing the data using OpenStat (Miller, 2010) or VassarStats (Lowry, 2010), which are free statistical analysis packages available online. Specifically, students need to decide which type of experimental design is used and which analysis would be appropriate (a one-way analysis of variance [ANOVA] with five levels). We use this data analysis to introduce ANOVA and post hoc statistical tests and why they are appropriate to analyze our data. As a post hoc test, we typically use Fisher's
Least Significant Difference test, which OpenStat does automatically at $p<0.05$ if a significant overall $\mathrm{F}$ ratio is obtained. (Details on our lesson on ANOVA and factors that can influence statistical power are available as part of the PowerPoint presentation, Lecture 3, available on our website: http://mdcune.psych.ucla.edu/modules/birdsong.)

Students characteristically obtain remarkably good data and invariably find significant differences. Data from one section of our students are displayed in Figure 4. Students are assigned to write a report in the form of a journal article and are guided through this process via discussion of the five objectives outlined above (also see PowerPoint slides in Lectures 3 and 4 on our website: http://mdcune.psych .ucla.edu/modules/birdsong).

Initially, we taught this module by interpreting the data for students. Both formal and informal feedback suggested that this "spoon feeding" wasn't desirable. Rather, students 


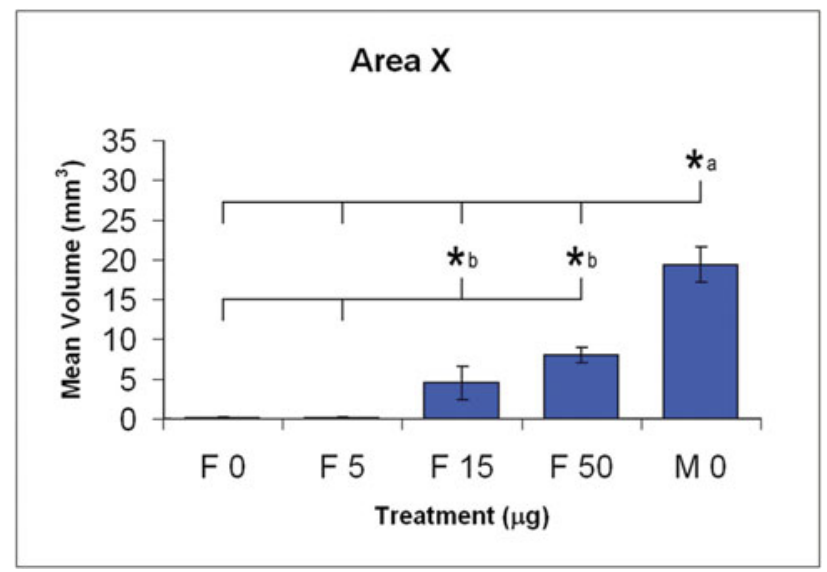

Figure 4. Mean Area $X$ volume $( \pm S E M)$ as a function of dose of $E_{2}$ $(0,5,15$, and $50 \mu \mathrm{g})$ and sex (M or F). Letter "a" signifies different from all other groups, letter " $\mathrm{b}$ " and brackets signify difference of 15 and $50 \mu \mathrm{g}$ doses from 5 and $0 \mu \mathrm{g}$, Fisher's Least Significant Difference test. Data were obtained by our students; only Area X data are shown here, but HVC and RA data show a similar pattern of significant differences.

indicated that they would appreciate the intellectual challenge of interpreting the data themselves, especially since they already had the five-question framework. Teaching the module without interpreting the data for students predictably led to significantly lower grades $[t(141)=2.088, p<0.05]$, with higher variance in scores, but the absolute difference in mean scores was only $3.13 \%$. The intellectual exercise seemed well justified.

\section{Implementing the Bird Song System Module}

This module works well with a class of 24 students, but it is adaptable for smaller or larger enrollments. We devote $3 \mathrm{wk}$ of 3-h labs and three 1-h lectures to this module. Students are easily able to complete their measurements and data analyses in this time. When we assign five birds (one from each condition) to each student, it takes about 3-5 h, maximum, for students to finish quantifying Area $\mathrm{X}, \mathrm{HVC}$, and RA in all of their birds. (This time includes orienting students to the ImageJ quantification tool and collecting all of their data in a master spreadsheet.) Data analyses are accomplished fairly quickly, but it takes much longer to explain the rationale and meaning of the analyses. Analyzing data, explaining their purpose, interpreting the results, and demonstrating how to present data in a meaningful manner takes a couple hours, which we usually distribute between lab and lecture. (See PowerPoint slides from Lectures 3 and 4.) Finally, as we are going through this project, we train students to write a journal-style lab report, and this effort usually takes $1-2 \mathrm{~h}$, which can either be in lecture or lab (again, see PowerPoint slides from Lectures 3 and 4).

Our students are either Psychobiology or Neuroscience juniors and seniors. Most students have had a course in statistics, and some have had exposure to neuroanatomy. Some have had some exposure to discussions on hormones and behavior, but most have not. Most have had a course in which they learn how to draft a journal article report. In teaching this module, we have found it useful to review relevant neuroendocrinology, neuroanatomy, statistics, and discussions on formulating a write-up. Notably, we discovered that, even when students have a background in statistics and writing journal-style reports, they still need a refresher tutorial. To assist faculty with these tutorials, we have provided PowerPoint presentations focusing on neuroendocrine background (Lectures 1 and 2), statistics (Lecture 3), and writing (Lectures 3 and 4). Thus, prerequisite courses are probably not necessary if the instructor provides relevant background on these topics. We use the exercise to reinforce statistical and writing skills that the students acquire in other courses, but this exercise also could be used to introduce these skills.

From the instructor's point of view, this teaching module is easy to implement. In teaching this unit, we identified and remedied many obstacles to make it a better learning experience for both students and instructors. Many common problems are addressed in the Complete Users' Manual and the FAQ list on our website.

\section{Possible Shorter Version of This Module}

Instructors could construct a module that would take less time but would still be informative by using fewer groups. For example, instructors could use the control females and control males along with the females treated with $50 \mu \mathrm{g}$ in order to demonstrate the sex difference and show that masculinization can be achieved by administering $\mathrm{E}_{2}$. Alternatively, instructors could use just the control males and control females to demonstrate the sex differences.

\section{Assessing the Effectiveness of This Module}

All assessment measures had IRB approval (UCLA IRB Exemption \#07-211). Efficacy of this module was assessed in two consecutive terms in lab classes composed of UCLA Neuroscience and Psychobiology majors. Both groups have very similar demographics and career ambitions. We administered a pretest and a posttest including a scale that assessed understanding of the content, statistics, and experimental design with a subscale of items that assessed "inappropriate thinking biases" based on those presented by Stanovich (2009). Students also completed a Materials Evaluation questionnaire that included Likert-scale items and an open-ended item to assess their experience with the module and their opinions about the materials provided. The open-ended question asked students to describe the purpose of the Bird Song System module from a learning standpoint. The pre/posttest and Student Materials Evaluation can be found in the Supplemental Material.

Because repeated testing itself can sometimes raise scores (Campbell and Stanley, 1963; Trochim, 1986, 2006), we administered the posttest alone in a second sample of students in a subsequent term. All students received the Materials Evaluation questionnaire, and their responses on this questionnaire were combined across both samples.

\section{RESULTS}

We compared the posttest scores to the pretest scores separately on our two scales: the module-specific and 


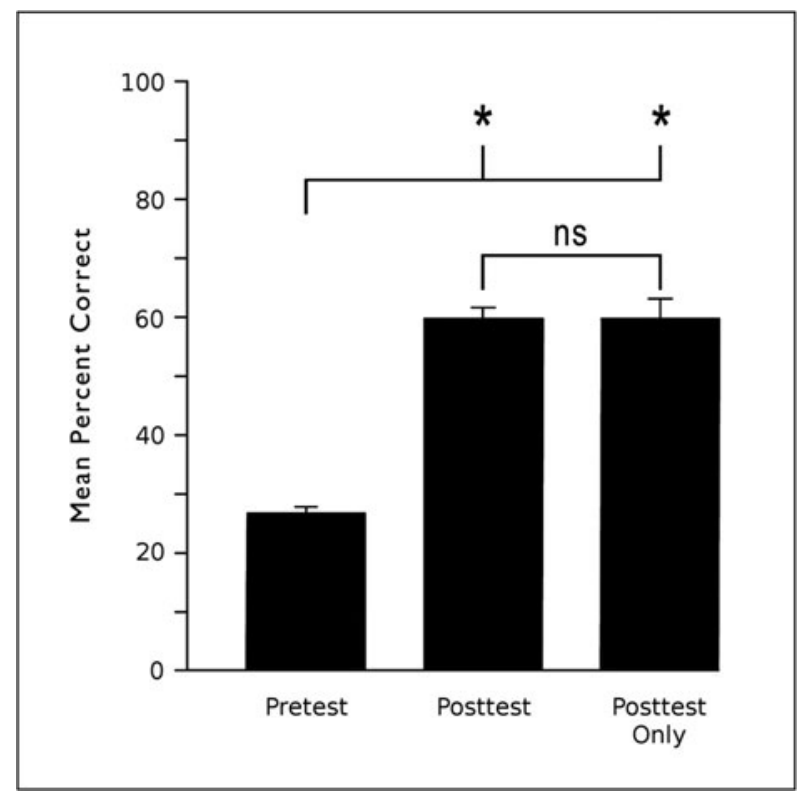

Figure 5. Mean percent correct $( \pm S E M)$ on pretest compared with posttest scores from two different academic terms; in posttest-only condition, pretest was not administered. ${ }^{*}, p<0.001 ; \mathrm{ns}=$ nonsignificant.

"inappropriate thinking biases" scales. One item on the module-specific scale was discarded because of poor psychometric properties (item \#15), which seemed to be poorly worded; the pattern of results was not appreciably altered by discarding this item. The posttest means on the modulespecific scale, addressing content, statistics, and experimental design, were significantly higher than the pretest of the first sample of students, $t(111)=17.78, p<0.001$, and $t(148)=$ $10.74, p<0.001$, respectively (Figure 5). The posttest means on the module-specific scale were not significantly different from each other, $t(148)=0.118, p=0.906$, suggesting that the gains between the posttest and pretest reflected genuine increases in learning and reasoning skills and not just an artifact of repeated testing (Figure 5). Also, grades on the module were not significantly correlated with pretest scores, $r(110)=0.06, p>0.50$, suggesting that better performance was not correlated with better preparation before the module. Posttest scores did correlate with grades on the module in both terms, $r(36)=0.37, p<0.05$ and $r(110)=0.33, p<0.05$, providing convergent validity for our module-specific pre/ posttest. Not surprisingly, scores on the four-item "inappropriate thinking biases" subscale (items 19-22 on the pre/posttest; see Supplemental Material) were uninfluenced by the module; students performed roughly at chance both before and after the module, and comparisons on this subscale were nonsignificant, all $p>0.50$ (data not shown).

Responses to the Likert-scale items reflected a general enthusiasm for the module and showed that students believed that they were gaining in knowledge and skills. Students generally agreed that they had learned a lot about sexual differentiation of the brain and data analysis (Figure 6). Students also liked getting significant results and repeating and extending a published experiment. Most students also reported that using the digitized images was easy, and they felt that
Table 1. Categorization of responses to the open-ended question "Please describe the purpose of using the Bird Song System module from a learning standpoint."

\begin{tabular}{lc}
\hline Category & Frequency \\
\hline Comprehension & 100 \\
Content & 89 \\
Experimental method & 57 \\
Data analysis & 40 \\
Writing skills & 36 \\
Hands-on experience & 24 \\
Extended relevance & 12 \\
Positive effect & 25 \\
Negative effect & 4 \\
\hline
\end{tabular}

A given student's responses can be coded in more than one category $(n=136$ students providing data on this item).

they learned as much from the digitized images as they would have from tissue on slides. (Notably, they had a side project that dealt with using actual tissue on slides, so they had an apt comparison.)

Students responded to the following open-ended prompt: "Please describe the purpose of using the Bird Song System module from a learning standpoint." Responses were coded as content-related ("sexual differentiation of the zebra finch," "role that estradiol plays on the female zebra finch system"), comprehension ("to learn," "to see," "give students a better grasp"), experimental method ("how a scientific study is produced from formulation of hypothesis to the data collection," "learn how to conduct a thorough research experiment"), data analysis ("students learned about ANOVA tests, how to justify and draw conclusions from data," "applying the statistics that I've learned. . . to "real" data, and build critical thinking skills by analyzing the data"), writing skills ("wrapping up all the ideas in a formal research article format," "formatting of a proper paper"), hands-on experience, extended relevance ("applicable to that of the human brain," "generalize to human beings," "connected to actual behaviors," "further studies in mammals"), positive affect ("excellent," "module did a great job," "Overall, I liked this module!" "It was very fun and enjoyable..."), and negative affect, which included all negative comments, whether regarding clarity or effectiveness of the materials. Table 1 presents the frequency of each response category.

\section{DISCUSSION}

This lab experience illustrates the organizational effect of gonadal steroids on brain development (Breedlove and Hampson, 2002), which occurs in early life during a critical/sensitive period and persists for the lifetime of the individual (Phoenix et al., 1959; Breedlove and Hampson, 2002). $E_{2}$ was administered when the birds hatched, yet the effects of this early exposure were still manifest in adulthood. Although the masculinization of the genetic females' song system is only partial, it is still impressive (see Figure 3).

In the course of this module, students learn how to do a careful image analysis, how to work with a large data 

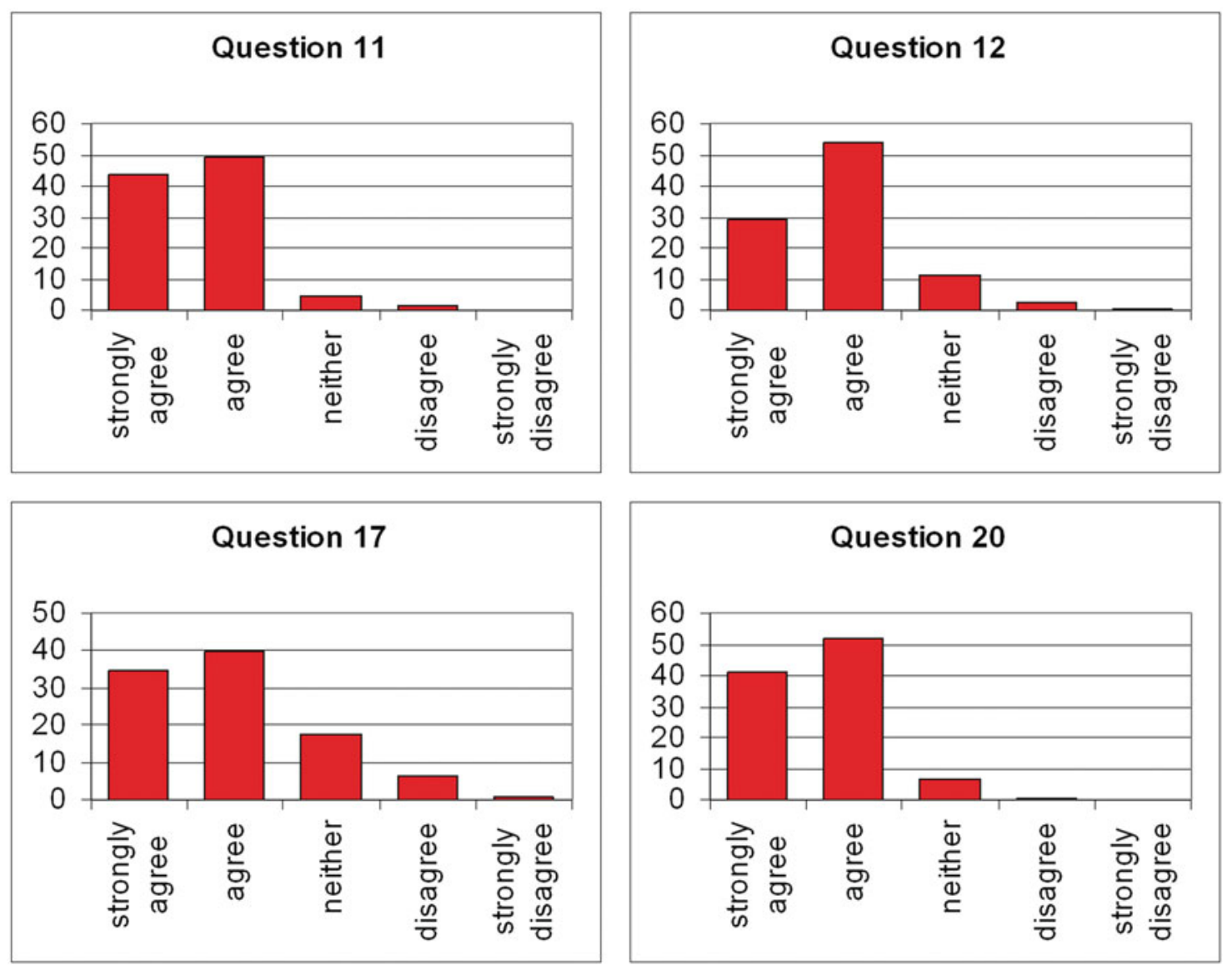

Figure 6. Responses to selected questions on our Likert scale; percent of total students in both samples combined ( $n=153)$ as a function of scale point (full set of responses and questions in the Supplemental Material). Question 11: I learned a lot about sexual differentiation of the brain through the Bird Song System module. Question 12: I learned a lot about analyzing data through the Bird Song System module. Question 17: I felt like I learned as much using the digitized images as I would have using tissue on slides. Question 20: I appreciated being able to jump right in and collect data.

set, how to perform inferential statistics (an ANOVA with post hoc tests), and how to interpret experimental findings. Further, they are exposed to control considerations to avoid possible confounds. The module-specific pre/posttest showed that students made significant gains in these domains (Figure 5). The significant correlations of module-specific posttest scores with grades suggest that the pre/posttest was tapping the same domain as did our assessment of students' write-ups. Our subscale of "inappropriate thinking biases" did not show any change as a function of instruction, and scores were roughly at chance in both the pretest and the posttest. This latter result is not surprising; these items largely test common thinking and heuristic biases (Stanovich and West, 2008), and these reasoning fallacies seem difficult to overcome. It was ambitious to hope that the short amount of experience with our module could reform such biases. Perhaps a different measure of critical thinking would have been more appropriate.

The open-ended item, which tapped students' impressions of the purpose of the module (Table 1), indicated that the experience enhanced students' understanding of experimental methodology and design, data analysis, and writing skills as well as content. Although affect wasn't explicitly queried in the open-ended item, positive comments outweighed negative by a ratio of $>5: 1$ (Table 1 ).

The Likert-scale questionnaire indicated that students agreed that they had learned a lot about content and data analysis (Figure 6). Further, students appreciated being able to obtain significant differences in their data. One advantage of this lab is that effect sizes and sex differences are so large that even inexperienced students can obtain data that will yield significant differences. In teaching this module across several terms, students have never failed to obtain data that yielded significant differences: students' data usually come out as they did in Figure 4. Thus, students obtain the sex differences described in the literature and can relate their results to published studies. Students find that, although the female song system is not exquisitely sensitive to estradiol $(5 \mu \mathrm{g}$ never masculinizes), usually $15 \mu \mathrm{g}$ is sufficient to masculinize the song system. Generally, students find that masculinization maximizes with a dose of $15 \mu \mathrm{g}$ and doesn't increase with a dose of $50 \mu \mathrm{g}$. Further, $50 \mu \mathrm{g}$, which is a massive dose, does not completely sex-reverse the song system. Usually, different parts of the song system don't show differential sensitivity to estradiol, but because this is an inquiry-based lab, students' data don't always come out the same way (see the Complete 
Users' Manual on the website for a discussion of anomalous results).

Students reported that using the digitized images was easy, and they felt that they learned as much from the digitized images as they would have from tissue on slides. Notably, we had students perform a side project in which they sectioned a zebra finch brain and then tried to determine the sex of their "mystery" bird by examining the song system. Although students seem to enjoy slicing and staining the actual tissue, we have found that using the image library is far superior to using the actual tissue on slides. When using the actual tissue, students and even graduate teaching assistants were observed wandering around the lower brainstem trying to find the song nuclei that are in the forebrain. Clearly, the image library focuses neophytes on the task better than using the actual tissue.

Our data suggest that this learning experience was an enjoyable and valuable one from the students' perspective. We have created the materials so that instructors can easily adopt the module. Further, no specialized equipment is required to provide this experience to students, only computers connected to the Internet. Due to their digital format, these materials can be incorporated into a standard classroom, a laboratory setting, or even distance learning.

All materials required for teaching this module, including the image library, the Complete Users' Manual, PDF handouts, PowerPoint slides with and without voice-over commentary, links to relevant websites, as well as lectures on the material, are available for free at http://mdcune.psych .ucla.edu/modules/birdsong. Grading keys/rubrics, keys to the treatment group for each bird, and instructor-specific materials also can be obtained for free by accessing http:/ / mdcune.psych.ucla.edu / faculty / create-a-faculty-account and setting up a faculty account.

\section{ACKNOWLEDGMENTS}

We thank A.-M. Schaaf for her help in preparing the manuscript and Jamie Crisostomo for help in formatting the manuscript. This study was supported by NSF CCLI DUE-0717306 (to W.G.) and a grant from the UCLA office of Instructional Development (to W.G.).

\section{REFERENCES}

Agate RJ, Grisham W, Wade J, Mann S, Wingfield J, Schanen C, Palotie A, Arnold AP (2003). Neural, not gonadal, origin of brain sex differences in a gynandromorphic finch. Proc Natl Acad Sci USA 100, 4873-4878.

Alvarez-Buylla A, Theelen M, Nottebohm F (1988). Birth of projection neurons in the higher vocal center of the canary forebrain before, during, and after song learning. Proc Natl Acad Sci USA 85, 87228726.

Borowski T, Ruiz ML, Fong M, Cui X, Grisham W (2010). Effects of indomethacin on the development of the song system in zebra finches. Neuroscience 2010 Abstracts. www.abstractsonline.com/Plan/ ViewAbstract.aspx?sKey=1bca6558-a510-4ee8-9a4c-c4d869714419\& $c K e y=5 f d b 2 d 6 f-a 24 a-4 c f d-9 d 69-214 b 6 e b 071 b 7 \& m K e y=\{$ E5D5C83F -CE2D-4D71-9DD6-FC7231E090FB\} (accessed 10 March 2011).

Bottjer SW, Mienser EA, Arnold AP (1984). Forebrain lesions disrupt development but not maintenance of song in passerine birds. Science $224,901-903$.
Breedlove SM, Hampson E (2002). Sexual differentiation of the brain and behavior. In: Behavioral Endocrinology, 2nd ed., ed. JB Becker, SM Breedlove, D Crew, and MM McCarthy, Cambridge, MA: MIT Press, 75-111. http://books.google.com/books?id $=$ D6TnKbTRBJoC\&printsec $=$ frontcover\&source $=$ gbs_ge_summary r $\&$ cad $=0 \# v=$ onepage $\& q \& \mathrm{f}=$ false (accessed 8 June 2010 ).

Brenowitz EA, Arnold AP (1986). Interspecific comparisons of the size of neural song control regions and song complexity in duetting birds: evolutionary implications. J Neurosci 6, 2875-2879.

Campbell DT, Stanley JC (1963). Experimental and QuasiExperimental Designs for Research on Teaching, Chicago, IL: Rand McNally.

Duncan KA, Jimenez P, Carruth LL (2009). The selective estrogen receptor-alpha coactivator, RPL7, and sexual differentiation of the songbird brain. Psychoendocrinology 34, S30-S38.

Grisham W, Arnold AP (1995). A direct comparison of the masculinizing effects of testosterone, androstenedione, estrogen, and progesterone on the development of the zebra finch song system. J Neurobiol 26, 163-170.

Grisham W, Lee J, Park SH, Mankowski JL, Arnold AP (2008). A dose-response study of estradiol's effects on the developing zebra finch song system. Neurosci Lett 445, 158-161.

Gurney ME, Konishi M (1980). Hormone-induced sexual differentiation of brain and behavior in zebra finches. Science 208, 13801383.

Johnson F, Bottjer SW (1992). Growth and regression of thalamic efferents in the song-control system of male zebra finches. J Comp Neurol 326, 442-450.

Lowry R (2010). VassarStats: Website for Statistical Computation. www.faculty.vassar.edu/lowry/VassarStats.html (accessed 19 June 2010).

McCasland JS (1987). Neuronal control of bird song production. J Neurosci 7, 23-39.

Miller B (2010). Bill Miller's Free Statistics Programs Site. www.statpages.org/miller/openstat/ (accessed 19 June 2010).

National Institutes of Health (NIH) (1997). ImageJ. http://rsb.info.nih.gov/ij (accessed 8 June 2010).

Nixdorf-Bergweiler BE, Bischof HJ (2007). A Stereotaxic Atlas of the Brain of the Zebra Finch, Taeniopygia Guttata, with Special Emphasis on Telencephalic Visual and Song System Nuclei in Transverse and Sagittal Sections, Bethesda, MD: National Library of Medicine, National Center for Biotechnology Information. www.ncbi.nlm.nih.gov/bookshelf/br.fcgi?book=atlas\&part $=$ atlas01 (accessed 8 June 2010).

Nordeen KW, Nordeen EJ (2004). Synaptic and molecular mechanisms regulating plasticity during early learning. Ann NY Acad Sci 1016, 416-437.

Nottebohm F (2005). The neural basis of birdsong. PLoS Biol 3, e164.

Nottebohm F, Arnold AP (1976). Sexual dimorphism in vocal control areas of the songbird brain. Science 194, 211-213.

Nottebohm F, Stokes TM, Leonard CM (1976). Central control of song in the canary, Serinus canarius. J Comp Neurol 165, 457-486.

Phoenix CH, Goy RW, Gerall AA, Young WC (1959). Organizing action of prenatally administered testosterone proprionate on the tissues mediating mating behavior in the female guinea pig. Endocrinology 65, 369-382.

Reiner A et al. (2004). Revised nomenclature for avian telencephalon and some related brainstem nuclei. J Comp Neurol 473, 377-414.

Roy A, Mooney R (2007). Auditory plasticity in a basal gangliaforebrain pathway during decrystallization of adult birdsong. J Neurosci $27,6374-6387$. 
Scharff C, Nottebohm F (1991). A comparative study of the behavioral deficits following lesions of various parts of the zebra finch song system: implications for vocal learning. J Neurosci 11, 28962913.

Schlinger BA, Soma KK, London SE (2001). Neurosteroids and brain sexual differentiation. Trends Neurosci 24, 429-431.

Stanovich KE (2009). Rational and irrational thought: the thinking that IQ tests miss. Sci Am Mind Nov/Dec, 34-39.

Stanovich KE, West RF (2008). On the relative independence of thinking biases and cognitive ability. J Pers Soc Psychol 94, 672-695.

Suthers RA, Margoliash D (2002). Motor control of birdsong. Curr Opin Neurobiol 12, 684-690.

Trochim WMK (1986). Advances in quasi-experimentation. In: Advances in Quasi-Experimental Design and Analysis, vol. 31, ed. WMK Trochim, San Francisco, CA: Jossey-Bass. www .socialresearchmethods.net/kb/advquasi.php (accessed 19 March 2009).

Trochim WMK 2006. Single Group Threats. www .socialresearchmethods.net/kb/intsing.php (accessed 19 March 2009).
Troyer TW, Doupe AJ (2000). An associational model of birdsong sensorimotor learning. II. Temporal hierarchies and the learning of song sequence. J Neurophys 84, 1224-1239.

Vu ET, Mazurek ME, Kuo YC (1994). Identification of a forebrain motor programming network for the learned song of zebra finches. J Neurosci 14, 6924-6934.

Wade J, Springer ML, Wingfield JC, Arnold AP (1996). Neither testicular androgens nor embryonic aromatase activity alters morphology of the neural song system in zebra finches. Biol Reprod 55, 11261132.

White SA, Fisher SE, Geschwind DH, Scharff C, Holy TE (2006). Singing mice, songbirds, and more: models for FOXP2 function and dysfunction in human speech and language. J Neurosci 26, 1037610379.

Williams H, Mehta N (1999). Changes in adult zebra finch song require a forebrain nucleus that is not necessary for song production. $\mathrm{J}$ Neurobiol 39, 14-28.

Xie F, London SE, Southey BR, Annangudi SP, Amare A, RodriguezZas SL, Clayton DF, Sweedler JV (2010). The zebra finch neuropeptidome: prediction, detection and expression. BMC Biol, 1-17. 